\title{
Peningkatan Kemampuan Menulis Karya Ilmiah melalui Workshop Penelitian Tindakan Kelas Guru SMA Negeri 1 Campalagian
}

\author{
Nurlina*1, Mutmainna ${ }^{2}$, Nursakinah Annisa Lutfin ${ }^{3}$, Mutiara Sabar ${ }^{4}$, Jenni Tasik Bintoen ${ }^{5}$ \\ 1,2,3,4,5Program Studi Pendidikan Fisika, Fakultas Keguruan dan Ilmu Pendidikan, \\ Universitas Sulawesi Barat \\ *e-mail: nurlina@unsulbar.ac.id ${ }^{1}$, mutmainna kadir@unsulbar.ac.id ${ }^{2}{ }_{2}$ nursakinahlutfin@unsulbar.ac.id $^{3}{ }_{\text {. }}$ \\ mutiarasabar15@gmail.com $_{2}^{4}$ jennimajene60@gmail.com ${ }^{5}$
}

\begin{abstract}
One of the teacher's self-development is by making scientific papers through the implementation of Classroom Action Research (PTK) and the results are published in scientific journals. From the results of the evaluation of activities obtained from previous community service and after observation to partner, SMA Negeri 1 Campalagian, it is necessary to hold a workshop to improve teacher understanding in preparing PTK. The method in this activity is through training and mentoring, which Is integrated into the PTK Workshop. This method was chosen to provide opportunities for teachers to experience step by step in the process of preparing PTK proposals. This activity was successfully carried out on July 17-18, 2021, followed by the preparation of a PTK proposal for one month. The teachers assessed that they had insight into possible PTK ideas and planning to do PTK. Most teachers also feel that this community service can help them to improve their professional competence as teachers.
\end{abstract}

Keywords: workshop, mentoring, teachers, classroom action research

\begin{abstract}
Abstrak
Salah satu pengembangan diri guru adalah dengan membuat karya tulis ilmiah melalui pelaksanaan Penelitian Tindakan Kelas (PTK) dan hasilnya dipublikasikan dalam jurnal ilmiah. Dari hasil evaluasi kegiatan yang diperoleh dari kegiatan pengabdian masyarakat sebelumnya dan setelah dilakukan observasi ke tempat mitra yaitu SMA Negeri 1 Campalagian, maka perlu diadakan workshop untuk meningkatkan pemahaman guru dalam mempersiapkan PTK. Metode dalam kegiatan ini adalah melalui pelatihan dan pendampingan yang diintegrasikan ke dalam Workshop PTK. Metode ini dipilih untuk memberikan kesempatan kepada guru untuk mengalami setiap langkah dalam proses penyusunan proposal PTK. Kegiatan ini berhasil dilaksanakan pada 17-18 Juli 2021, dilanjutkan dengan penyusunan proposal PTK selama satu bulan. Melalui kegiatan ini, guru menilai bahwa mereka memiliki wawasan tentang kemungkinan ide PTK dan berencana untuk melakukan ptk. Sebagian besar guru juga merasa bahwa kegiatan ini dapat membantu mereka untuk meningkatkan kompetensi profesionalnya sebagai guru.
\end{abstract}

Kata kunci: workshop, pendampingan, guru, penelitian tindakan kelas.

\section{PENDAHULUAN}

Guru sebagai pendidik profesional memiliki beberapa tugas utama yaitu mendidik, mengajar, membimbing, mengarahkan, menilai dan mengevaluasi. Guru merupakan suatu profesi yang memiliki peranan penting dalam menyiapkan sumber daya manusia yang berkualitas dan merupakan kunci utama penentu keberhasilan pendidikan (Sofwan et al., 2020). Dalam proses pembelajaran, guru memiliki tanggung jawab untuk meningkatkan kompetensi peserta didik dan hal tersebut tidaklah mudah (Milandari et al., 2019). Olehnya itu, guru merupakan suatu profesi yang didalamnya membutuhkan pengetahuan, keterampilan, dan penguasaan terhadap bahan ajar yang terdapat dalam kurikulum serta menuntut adanya kesediaan untuk senantiasa mengembangkan diri dalam menjalani profesi tersebut. Beberapa pengembangan profesi guru yang memiliki nilai kredit antara lain: membuat karya tulis atau karya ilmiah di bidang pendidikan, menemukan teknologi tepat guna, membuat alat pelajaran atau alat peraga, dan menciptakan karya seni (Sudjana et al., 2001).

SMA Negeri 1 Campalagian yang terletak sejauh 19 km dari Universitas Sulawesi Barat merupakan salah satu sekolah yang berada di Kabupaten Polewali Mandar tepatnya di jalan 
Poros Majene, Desa Lapeo, Kec. Campalagian, Kab. Polewali Mandar, Sulawesi Barat. Melalui kegiatan observasi yang dilakukan di sekolah tersebut, diperoleh data kemampuan guru untuk melakukan pengembangan diri selain dari tugas pokoknya yaitu melakukan pengajaran dalam bidang pendidikan. Kemampuan guru dalam melakukan penelitian secara mandiri guna mengembangkan inovasi dalam pembelajaran dan mempublikasi hasil karya ilmiah sebagai temuan dari penelitiannya masih sangat kurang. Hal ini terlihat dari data sekolah yang menunjukkan bahwa dua tahun terakhir hanya $10 \%$ guru yang dapat melakukan Penelitian Tindakan Kelas (PTK). PTK merupakan pencermatan terhadap kegiatan belajar berupa sebuah tenaga yang sengaja dimunculkan dan terjadi dalam sebuah kelas secara bersama (Arikunto et al., 2006). Untuk meningkatkan kualitas pembelajaran yang merupakan salah satu tuntutan kompetensi guru, guru harus mampu melakukan PTK (Slameto, 2015).

Dalam kaitannya dengan peranan Prodi Pendidikan Fisika untuk ikut memajukan bidang Pendidikan khususnya di Provinsi Sulawesi Barat, telah dilakukan berbagai kegiatan pengabdian kepada masyarakat (PkM). Salah satu diantaranya, melalui kegiatan Program PkM dengan judul "Workshop Penulisan Artikel Ilmiah Guru SMP Kecamatan Tinambung Kabupaten Polewali Mandar". Dari kegiatan tersebut, diperoleh data bahwa salah satu kendala guru dalam menyusun artikel ilmiah adalah sebagian besar guru belum melakukan penelitian sehingga hasil penelitian yang menjadi bahan utama dalam penyusunan artikel ilmiah tidak dapat dilaksanakan secara optimal. Hal serupa juga terjadi di SMA Negeri 1 Campalagian (Mutmainna et al., 2018). Data ini didukung dengan adanya penyampaian kepihak Prodi Pendidikan Fisika dari pihak sekolah meminta untuk diberikan kegiatan pelatihan terkait dengan peningkatan kemampuan menulis karya ilmiah khususnya PTK.

Dengan adanya hasil evaluasi kegiatan yang diperoleh dari kegiatan tersebut dan setelah melakukan kegiatan observasi ke calon mitra PkM, maka dari segi sumber daya yang dimiliki oleh tim dosen Prodi Pendidikan Fisika, dipandang perlu untuk dilakukan suatu kegiatan berupa pelatihan atau workshop untuk menyelesaikan permasalahan tersebut. Atas pertimbangan itulah, maka diusulkan salah satu kegiatan PkM dengan judul "Peningkatan Kemampuan Menulis Karya Ilmiah melalui Workshop PTK Guru SMAN 1 Campalagian"

Permasalahan yang dihadapi oleh para guru di SMA Negeri 1 Campalagian adalah rendahnya kemampuan guru dalam mempublikasikan artikel ilmiah sebagai akibat dari persentase guru yang membudayakan melakukan PTK masih sangat rendah. Alasan terkuat lainnya yang membuat guru kurang tertarik melakukan PTK adalah karena merasa sudah terlalu sibuk dengan berbagai urusan administrasi dan belum adanya sosialisasi secara menyeluruh tentang bagaimana melaksanakan penelitian yang baik dan benar (Chairunnisa et al., 2020). Para guru berharap dapat memperoleh bimbingan dalam melakukan penelitian secara berkala dan dapat mempublikasikan hasil temuannya melalui penulisan artikel ilmiah. Dengan kegiatan Peningkatan Kemampuan Menulis Karya Ilmiah melalui Workshop PTK Guru SMAN 1 Campalagian ini, diharapkan akan dapat membantu guru dalam mengembangkan inovasi dalam pembelajaran dan juga dapat memenuhi persyaratan untuk kenaikan jabatan fungsional.

Berdasarkan uraian permasalahan tersebut, maka pihak sekolah selaku mitra merasa amat perlu mendapat bekal berupa bimbingan dan pengetahuan dalam melakukan penelitian secara berkala dan dapat mempublikasikan hasil temuannya melalui kegiatan Program PkM dalam Peningkatan Kemampuan Menulis Karya Ilmiah melalui Workshop PTK Guru SMA Negeri 1 Campalagian. Berdasarkan paparan di atas, beberapa permasalahan yang dihadapi mitra adalah: (1) rendahnya pemahaman guru SMA Negeri 1 Campalagian dalam melakukan PTK, dan (2) rendahnya pemahaman guru SMA Negeri 1 Campalagian dalam mempublikasikan artikel ilmiah. 


\section{METODE}

Sasaran pelaksanaan pengabdian ini adalah guru-guru SMA Negeri 1 Campalagian. Metode yang digunakan dalam kegiatan ini adalah melalui pelatihan dan pembimbingan/pendampingan yang terintegrasi dalam kegiatan Workshop PTK secara daring. Metode ini dipilih untuk memberi kesempatan kepada guru-guru agar bisa mengalami sendiri langkah demi langkah dalam proses penyusunan proposal PTK yang sesuai dengan permasalahan pembelajaran yang dihadapi oleh para guru di kelas masing-masing.

Secara ringkas, langkah-langkah pelaksanaan kegiatan pengabdian ini ditunjukkan pada Gambar 1.

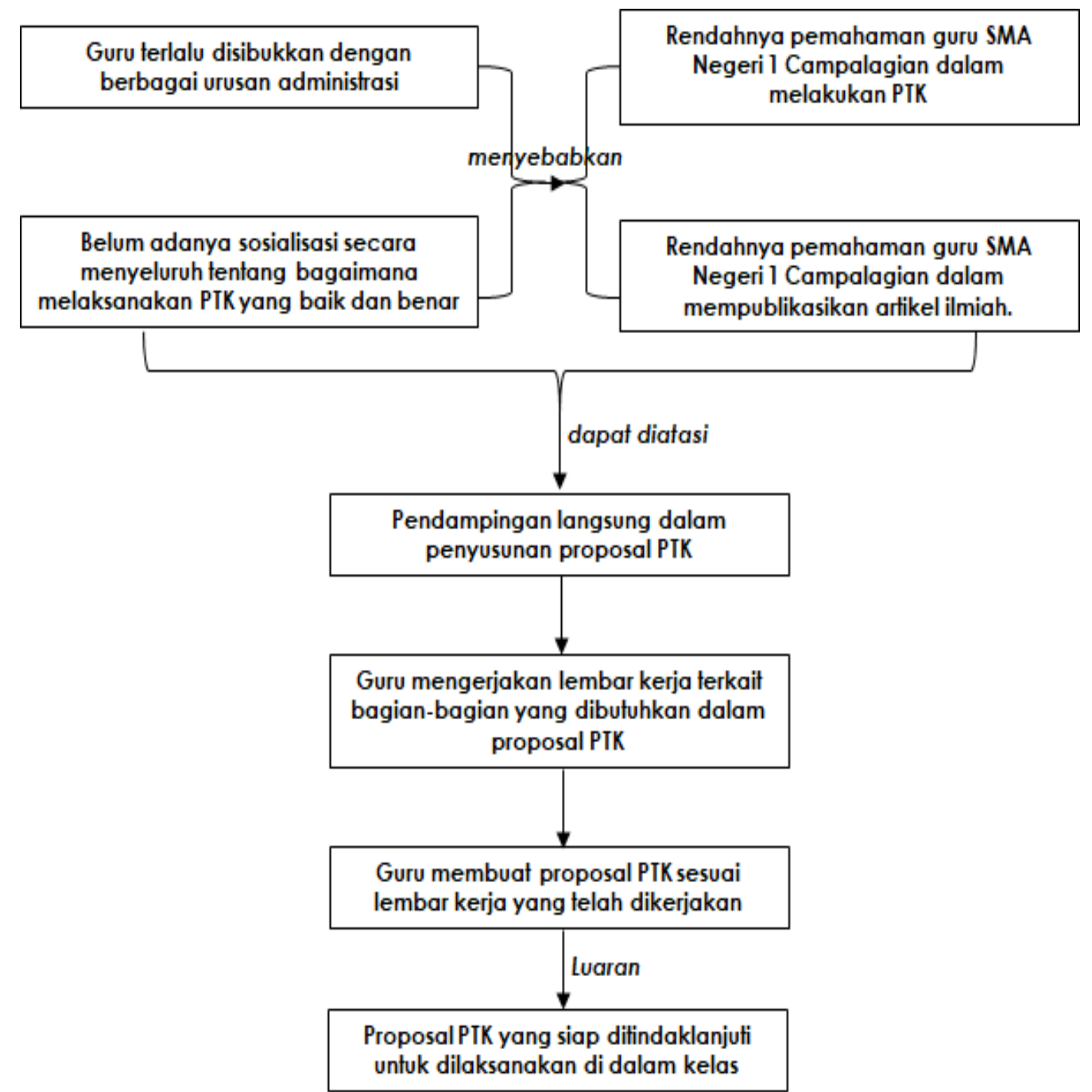

Gambar 1. Metode pelaksanaan workshop PTK

\section{HASIL DAN PEMBAHASAN}

\section{Koordinasi dengan Tim Kerja}

Langkah awal dalam kegiatan pengabdian ini adalah melakukan koordinasi bersama tim kerja melalui rapat perdana. Hal ini dilakukan untuk menyamakan visi dan misi dalam pelaksanaan kegiatan. Selain itu, rapat perdana ini merupakan waktu yang tepat untuk melakukan pembagian tugas agar kegiatan dapat berjalan dengan optimal. Pembagian tugas dalam pada kegiatan pengabdian ini dapat dilihat pada Tabel 1. 
Tabel 1. Susunan panitia workshop PTK

\begin{tabular}{cc}
\hline Peran & Nama \\
\hline Ketua & Nurlina, S.Pd., M.Si. \\
Sekretaris & Mutmainna, S.Pd., M.Pd. \\
Bendahara & Nursakinah Annisa Lutfin, S.Pd., M.Si. \\
Seksi Acara & Mutiara Sabar \\
Seksi Publikasi dan Dokumentasi & Jenni Tasik Bintoen \\
\hline
\end{tabular}

\section{Koordinasi dengan Sekolah Mitra}

Koordinasi dengan sekolah mitra yaitu SMA Negeri 1 Campalagian diawali dengan membuka komunikasi dengan Kepala SMA Negeri 1 Campalagian terkait usulan kegiatan pengabdian sekaligus melakukan survei awal ke calon mitra.

\section{Pelaksanaan Kegiatan Workshop PTK}

Kegiatan PkM ini dilakukan dengan mengadakan Workshop PTK yang bekerjasama dengan SMA Negeri 1 Campalagian. Tujuan dari kegiatan ini adalah untuk membangun budaya bagi guru SMA Negeri 1 Campalagian dalam melakukan penelitian tindakan kelas secara berkala. Pelaksanaan PTK secara berkala dapat melatih guru SMA Negeri 1 Campalagian menjadi peka dan kritis terhadap dinamika proses pembelajaran di kelas, sehingga para guru dapat mengidentifikasi masalah serta senantiasa mengupayakan perbaikan dan inovasi yang dapat meningkatkan mutu pembelajaran di dalam kelasnya. Selain itu, kegiatan ini juga mendorong guru SMA Negeri 1 Campalagian untuk menerapkan PTK dalam pendidikan dan pembelajaran, dan menumbuhkan budaya meneliti pada komunitas guru di SMA Negeri 1 Campalagian.

Workshop PTK ini diadakan selama 2 hari yaitu 17 - 18 Juli 2021 melalui zoom meeting. Hari pertama (Sabtu, 17 Juli 2021), kegiatan diawali dengan pembukaan kegiatan pengabdian yang terdiri atas sambutan dari Ketua Tim Pelaksana Pengabdian yang kemudian dilanjutkan oleh Kepala SMA Negeri 1 Campalagian. Kegiatan Workshop dibuka secara langsung oleh Dekan FKIP Unsulbar. Setelah acara pembukaan, kegiatan dilanjutkan dengan pemberian materi oleh Dr. Abdullah Pandang, M.Pd. dengan materi "Apa dan Bagaimana Penelitian Tindakan Kelas" yang dapat dilihat pada Gambar 2a dan 2b.

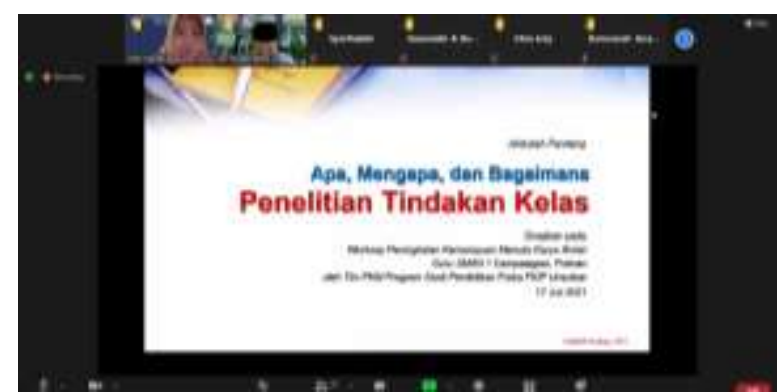

(a)

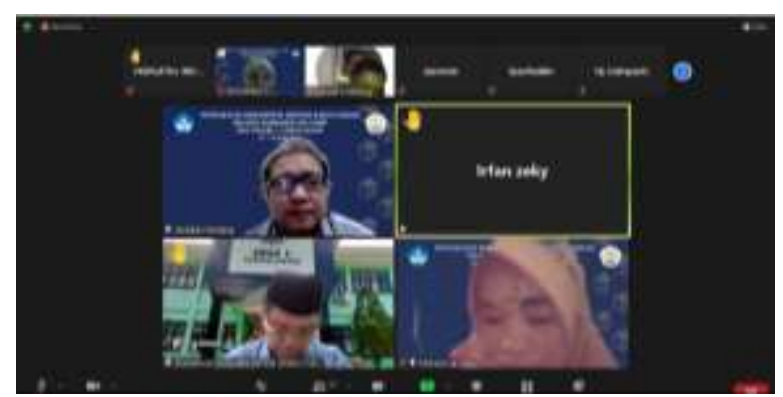

(b)

Gambar 2. (a) Paparan materi workhshop hari ke-1 (b) Gambaran pelaksanaan workshop hari ke-1

Pemaparan dari Pemateri 1 ini memberi penjelasan terkait alur pikir PTK, perbandingan PTK dan riset konvensional, proses dan siklus PTK, dan memberikan contoh langsung bagaimana menyusun proposal PTK. Untuk memberikan pengalaman langsung kepada guruguru SMA Negeri 1 Campalagian, setelah penyampaian materi oleh Pemateri 1, kegiatan 
dilanjutkan dengan membagi peserta workshop kedalam 4 kelompok dan dimasukkan ke breakout room zoom meeting dengan didampingi oleh masing-masing pendamping. Pada kegiatan itu, para peserta diajak untuk mengerjakan 3 lembar kerja penyusunan proposal PTK yang telah disiapkan oleh Pemateri 1 yaitu 1) Analisis Masalah; 2) Perumusan Judul PTK; dan 3) Perumusan Latar Belakang dan Rumusan Masalah.

Kegiatan pada hari kedua (18 Juli 2021) dilanjutkan dengan pemberian materi oleh Dr. Khaeruddin, S.Pd., M.Pd. dengan "Teknik Pembuatan Instrumen dan Pengumpulan Data" yang dapat dilihat pada Gambar 3a dan 3b. Pemaparan dari Pemateri 2 ini memberi penjelasan terkait sasaran PTK, contoh-contoh judul PTK dan rencana tindakannya, serta teknik dan bentuk instrumen. Sama halnya kegiatan pada hari pertama, kegiatan dilanjutkan dengan memberikan pengalaman langsung kepada guru-guru SMA Negeri 1 Campalagian untuk melanjutkan lembar kerja terkait penyusunan proposal PTK di breakout room zoom meeting (Gambar 4). Lembar kerja yang dikerjakan pada hari kedua adalah 1) Perumusan Kajian Teori; 2) Metode Penelitian PTK; dan 3) Penyusunan Instrumen PTK (RPP).

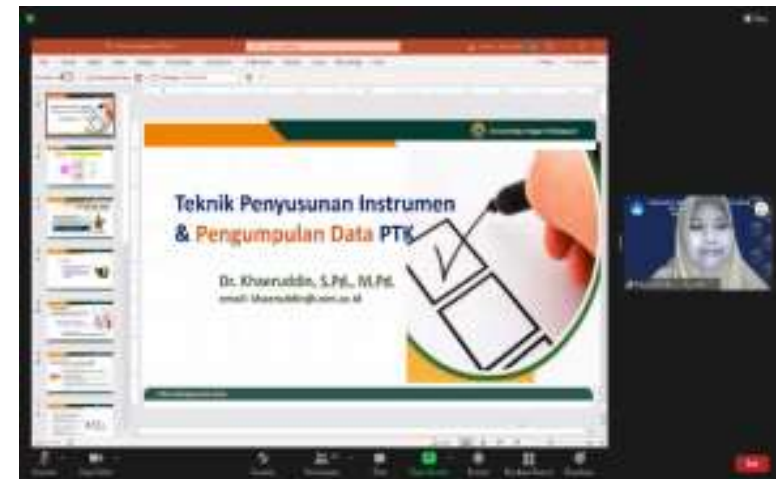

(a)

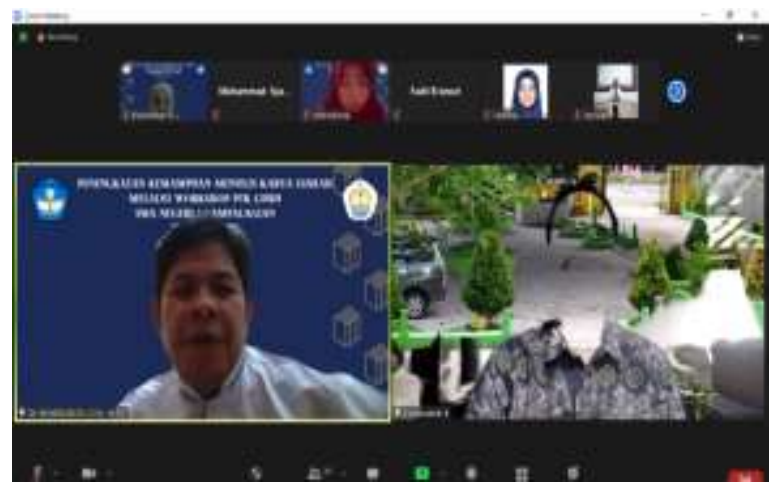

(b)

Gambar 3. (a) Paparan materi workhshop hari ke-2 (b) Gambaran pelaksanaan workshop hari ke-2

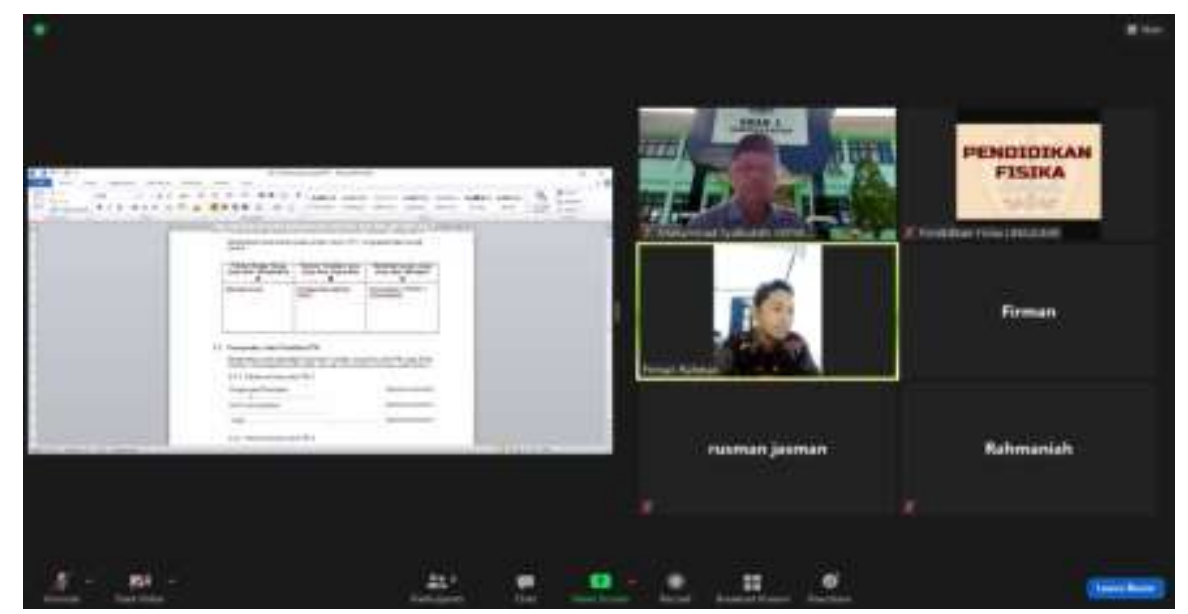

Gambar 4. Proses pendampingan penyusunan proposal PTK melalui fitur breakout room zoom meeting

Kegiatan ini diakhiri dengan memberikan apresiasi kepada beberapa guru yang telah mengumpulkan dan menyelesaikan dengan baik lembar kerja penyusunan PTK. Setelah itu, sambutan dari salah satu perwakilan guru SMA Negeri 1 Campalagian mengatakan bahwa kegiatan pengabdian ini sangatlah berarti dan bermanfaat bagi guru-guru dan berharap agar kedepannya kegiatan pengabdian seperti ini dapat dilaksanakan kembali dengan bentuk kegiatan lainnya yang tentunya berorientasi pada peningkatan kompetensi guru. Sambutan akhir dari Ketua Tim Pelaksana Pengabdian menyampaikan beberapa hal terkait teknis pengumpulan Proposal PTK yang akan dibuat oleh guru-guru peserta workshop berdasarkan 
lembar kerja yang telah dikumpulkan. Kegiatan ini dilanjutkan dengan memberikan kesempatan kepada guru-guru SMA Negeri 1 Campalagian untuk menyusun proposal PTK berdasarkan lembar kerja yang telah dikerjakan. Proses pengumpulan PTK dilakukan selama 1 bulan melalui form yang telah disediakan oleh tim pelaksana.

Permasalahan dari mitra guru-guru di SMA Negeri 1 Campalagian adalah rendahnya pemahaman guru SMA Negeri 1 Campalagian dalam melakukan PTK dan rendahnya pemahaman guru dalam mempublikasikan artikel ilmiah. Hal ini sejalan dengan kegiatan pengabdian yang berjudul Pelatihan dan Pendampingan Penyusunan Proposal Penelitian Tindakan Kelas (PTK) Bagi Guru-Guru SDN Gugus 2 Mataram. Permasalahan yang dialami para guru adalah kurang mempunyai pengetahuan dan keterampilan (Nisa et al., 2019). Selain itu, motivasi yang kurang dalam menyusun dan membuat PTK juga menjadi penyebab rendahnya pemahaman guru dalam mempublikasikan artikel ilmiah (ZM et al., 2019). Kemampuan menulis karya ilmiah merupakan dasar yang diperlukan guru untuk melakukan PTK. PTK merupakan suatu keharusan dan kebutuhan yang penting bagi guru dalam meningkatkan mutu proses pembelajaran dan kualitas peserta didik. Selain itu, PTK juga penting untuk pengembangan karir para guru.

Solusi yang diusulkan untuk mengatasi permasalahan mitra guru-guru SMA Negeri 1 Campalagian adalah melaksanakan Workshop PTK. Terdapat beberapa target luaran yang diharapkan tercapai setelah pelaksanaan workshop ini yaitu meningkatkan pemahaman guru SMA Negeri 1 Campalagian dalam mengembangkan diri untuk melakukan PTK secara berkala, meningkatkan kemampuan guru SMA Negeri 1 Campalagian dalam menulis artikel ilmiah, dan dihasilkannya proposal PTK dari setiap guru SMA Negeri 1 Campalagian yang menjadi peserta coaching. Proposal PTK yang dihasilkan oleh para guru SMA Negeri 1 Campalagian diharapkan dapat terlaksana sampai tahap penelitian, pembuatan artikel ilmiah, dan publikasi.

Kegiatan ini diharapkan dapat membangun budaya bagi guru SMA Negeri 1 Campalagian dalam melakukan PTK secara berkala. Pelaksanaan PTK secara berkala dapat melatih guru SMA Negeri 1 Campalagian menjadi peka dan kritis terhadap dinamika proses pembelajaran di kelas, sehingga para guru dapat mengidentifikasi masalah serta senantiasa mengupayakan perbaikan dan inovasi yang dapat meningkatkan mutu pembelajaran di dalam kelasnya (Nasirun et al., 2020).

\section{KESIMPULAN}

Program PkM melalui Workshop PTK ini merupakan salah satu solusi yang tepat untuk meningkatkan kemampuan guru dalam penyusunan proposal dan melakukan penelitian PTK. Kegiatan ini berhasil terselenggara dengan baik pada tanggal 17-18 Juli 2021 yang dilanjutkan dengan penyusunan proposal PTK selama 1 bulan. Para guru menganggap bahwa setelah mengikuti workshop PTK, mereka memiliki wawasan tentang kemungkinan ide PTK yang kondusif untuk dilakukan dan berencana untuk melakukan PTK. Sebagian besar guru juga merasa bahwa kegiatan ini dapat membantu mereka untuk meningkatkan kompetensi profesional sebagai guru.

\section{UCAPAN TERIMA KASIH (Bila Perlu)}

Penulis mengucapkan terima kasih kepada Universitas Sulawesi Barat yang telah memberi dukungan finansial terhadap kegiatan pengabdian ini.

\section{DAFTAR PUSTAKA}

Arikunto, S., Suhardjono, \& Supardi. (2006). Penelitian Tindakan Kelas. Jakarta: Bumi Aksara.

Chairunnisa, C., Istaryatiningtias, \& Khuluqo, I. El. (2020). Pemberdayaan Guru Melalui Pelatihan Penelitian Tindakan Kelas. Jurnal PKM: Pengabdian Kepada Masyarakat, 03(01), 22-30. 
https://doi.org/http://dx.doi.org/10.30998/jurnalpkm.v3i1.5180

Milandari, B. D., Waluyan, R. M., Mus, A. H., Nurmiwati, \& Haifaturrahmah. (2019). Pelatihan Penyusunan Penelitian Tindakan Kelas pada Guru Bahasa Indonesia dalam Upaya Peningkatan Kualitas Pembelajaran di SMA Negeri 1 Labuapi. Journal of Character Education Society, 2(2), 85-92. https://doi.org/https://doi.org/10.31764/jces.v2i2.1722

Mutmainna \& Hamzah, H. (2018) Laporan PkM Penulisan Artikel Ilmiah Guru SMP Kecamatan Tinambung Kabupaten Polewali Mandar Provinsi Sulawesi Barat. Majene: LPPM \& PM Universitas Sulawesi Barat.

Nasirun, Yulidesni, Indrawati, \& Qalbi, Z. (2020). Pelatihan Penyusunan Proposal Penelitian Tindakan Kelas Bagi Guru di Taman Kanak-Kanak Al-Jundi Kota Bengkulu. Jurnal Pengabdian Kepada Masyarakat, 1(1), 13-18.

Nisa, K., Darmiany, Gunayasa, I. B. K., \& Khair, B. N. (2019). Pelatihan dan Pendampingan Penyusunan Proposal Penelitian Tindakan Kelas (PTK) Bagi Guru-Guru SDN Gugus 2 Mataram. Jurnal Pendidikan Dan Pengabdian Masyarakat, 2(2), 269-274.

Slameto. (2015). Penyusunan Proposal Penelitian Tindakan Kelas. Scholaria : Jurnal Pendidikan Dan Kebudayaan, 60-69. https://doi.org/https://doi.org/10.24246/j.scholaria.2015.v5.i2.p60-69

Sofwan, M., Alirmansyah, \& Pratama, R. (2020). Workshop Penyusunan Proposal, Pelaksanaan, dan Laporan Hasil Penelitian Tindakan Kelas (PTK) bagi Guru di SD Negeri No.10/IV Kota Jambi. BAKTIMAS: Jurnal Pengabdian Pada Masyarakat, 2(4), 181-187. https://doi.org/10.32672/btm.v2i4.2467

Sudjana, Nana, \& Laksamana, U. (2001). Menyusun Karya Ilmiah untuk Memperoleh Angka Kredit. Bandung: Sinar Baru Algensindo.

ZM, H., Sukardi, \& Suryanti, N. M. N. (2019). Penyusunan Proposal Penelitian Tindakan Kelas (PTK) Bagi Guru-Guru MTs dan MA Di Kecamatan Woja Kabupaten Dompu. Jurnal Pengabdian Magister Pendidikan IPA, 2(1), 1-3. https://doi.org/10.29303/jpmpi.v1i2.220 